\title{
Influencing Parental Behaviors Through an Orientation Program
}

\author{
by Susan A. Woollen (sawooll@ilstu.edu), Academic Adviser, Department of Criminal \\ Justice Sciences, Illinois State University.
}

A mother edits her son's college papers and complains directly to his professor when a low grade is assigned to one. A father contacts an academic adviser to raise objections about an 8 a.m. class that appears on his son's schedule. Another mother leads her senior-level son around the campus's career fair, speaking with prospective employers for him.

These are only a few of the examples of what staff members at Illinois State University (ISU), a doctoral research-intensive institution with an undergraduate enrollment of 17,000, describe as inappropriate behaviors displayed by parents of college students. According to university officials, these behaviors are not isolated incidents and have become more frequent and typical of today's parents. Although the university has acknowledged parental involvement in the past, staff and faculty now are being challenged by intrusive behaviors. This article focuses on ISU's attempt to influence parental behaviors through separation and communication during its freshman orientation program, which primarily serves traditional freshman students (18-19 years old) and their parents.

University representatives use direct-redirect communication techniques as one means to emphasize the role of the student. For example, the orientation guides are trained to direct and/or redirect comments, as appropriate, to the student. At check-in, many parents will take charge and attempt to register the family. In this situation, the orientation guide will say that he or she needs to speak to the student and will wait until the student comes to the front. One parent is overheard saying, "You're right. I need to take a backseat now." Many other parents are persistent, but the guides are trained to get the student's attention. This sets the stage for parents to see students as the focal point, as well as encouraging students to speak for themselves.

In speaking with parents, the parent services coordinator suggests that they learn to redirect problems to their students. As an example, he warns that a few parents may get an early morning telephone call during the first week of classes, with their student stating, "I hate it here." The office prefers that the parent allow the student 24 hours to first work out the problem on his or her own or that the parent ask if the student has tried the services that are designed to help him or her become a responsible problem solver. If a mother or father calls Parent Services about a child's problem, the office staff will first ask, "What has your student done to rectify the situation?" Although parents can intervene if they believe they need to get involved, the coordinator suggests that parents 
consult with his office first. This provides the university the opportunity to reinforce with parents the strategy of redirection to the student.

Another communication technique to help parents develop an understanding of their students' growing independence is to refer to "sons or daughters" as "students." Orientation presenters use the word "student" to clarify the role of the child at the university. Parents are told that this may be "your child" but he or she is "our student." This helps explain one of the major differences between high school and college-the college student has greater responsibilities and will be held accountable for his or her behaviors.

ISU's orientation program contains a student and parent component. According to the orientation coordinator, certain programming events are merged and others separated in order to "alleviate handholding." If parents and students are separated, it provides an opportunity for parents to let their children make decisions, while allowing the children to get acquainted with the new role of being a student.

After the families are checked in for the program, students are sent to a designated residence hall where they meet their orientation guides and break into small groups. The students are grouped together for logistical purposes, as well as to help them begin to bond with each other. The parents are directed to a large lecture hall and instructed to sit in the middle section. The orientation coordinator welcomes them and provides information about the program's format. Parents are informed that orientation is designed to "give them (children) back to you and take them away." In a sense, this statement is prophetic of the separation that will be occurring at the end of summer. After parents hear from the coordinators of orientation and parent services, the orientation leaders escort their student groups into the hall; however, the students sit in the two wings adjacent to the parents.

The orientation coordinator begins the program with an honest assessment of potential problems but couples it with assurance that the university will provide necessary services for students to resolve their concerns: "ISU is not a perfect place. It is large. Red tape exists. Students will have to hit some walls in order to solve some problems. But there are many helpful people on this campus because this campus is about the people. We will take care of them."

Immediately following this announcement, the coordinator of parent services is introduced. His placement as the first official speaker in the program emphasizes the importance of parents to the university. He begins his presentation by describing his office as the link between parents and the campus, and emphasizes how important parents are to the university community. In a thoughtful manner, he provides several suggestions about what parents should do if their student contacts them with a complaint.

The parent group also attends a session entitled "Family and University" in which the associate dean of students mentions how their children are no longer considered adolescents but adults. Although they want to be adults, they may sometimes act like adolescents and demonstrate immature behaviors. The speaker asserts that students need to make decisions on their own and accept responsibility for their actions. He also provides several suggestions about how parents can help promote student development. 
After "Family and University," the parents attend a session called "Now that They Are College Students," which is facilitated by a counselor from the Student Counseling Center. He asks parents questions about how their lives will be different without this young person living in their homes. Both mothers and fathers are quick to participate, as if they have been waiting for an opportunity to share and express their fears and excitement about the impact the future separation will have on their relationships.

What are the strategies and suggestions presented during the course of these parent sessions? In each meeting, the university representative makes it clear that parents are the experts about their children, not about the university. The role of parents changes because the child is treated as an adult by the university. The university, using its experience and knowledge about college student behavior, strongly recommends that parents respect their students' space, such as not making unannounced visits or expecting their students to return phone or e-mail messages immediately.

The speakers also acknowledge that the university recognizes that some parents will have difficulty in letting their children go. The associate director of student affairs tells parents that the university understands their concerns but that it is time "to let them (the students) become confident in their abilities to resolve their own problems." The role of parents of college students is different than it is for high school students; so parental involvement is welcomed but too much involvement may prevent students from developing effective problem-solving techniques. The coordinator of parent services expresses the same message by suggesting that parent intervention in most situations is not considered helpful, and that it will be best for parents not to be directly involved. He also states that "parents may be frustrated because they are used to taking care of things, but the student now needs to take responsibility." The counselor suggests that parents consider how the lack of control and power will affect their relationships with their children. Parents will need to consider hardships as opportunities because failing can be the stimulus to help an individual grow and develop.

It is difficult to evaluate whether these intentional messages for parents achieve their purpose. Parent advisory groups could serve as focus groups for qualitative assessment efforts, and parent surveys following orientation may yield some useful quantitative data as parents gain some distance from the orientation experience. Future research should utilize parental interviews during orientation and follow-up interviews after enrollment to determine if the current strategies were considered and utilized by participants. Thus, the university could evaluate if its conveyed messages were actually comprehended and if those messages did, in fact, influence parental behaviors. 